\title{
O consumo de bebidas alcoólicas e tabaco entre acadêmicos do curso de Odontologia do Centro Universitário de Patos de Minas - UNIPAM
}

\author{
Consumption of alcoholic beverages and tobacco among students of the Dentistry course of the \\ University Center of Patos De Minas - UNIPAM \\ Consumo de bebidas alcohólicas y tabaco entre estudiantes del curso de Odontología del Centro \\ Universitario de Patos de Minas - UNIPAM
}

Recebido: 03/12/2021 | Revisado: 09/12/2021 | Aceito: 11/12/2021 | Publicado: 20/12/2021

Laura Peres

ORCID: https://orcid.org/0000-0002-9709-6795 Centro Universitário de Patos de Minas, Brasil E-mail: lauraperes@unipam.edu.br Helvécio Marangon Júnior ORCID: https://orcid.org/0000-0002-9709-6795 Centro Universitário de Patos de Minas, Brasil E-mail: helveciomjr@unipam.edu.br

Rodrigo Soares de Andrade ORCID: https://orcid.org/0000-0001-6114-0929 Centro Universitário de Patos de Minas, Brasil E-mail: rodrigosa@unipam.edu.br

Marcos Bilharinho de Mendonca ORCID: https://orcid.org/0000-0002-0225-9687 Centro Universitário de Patos de Minas, Brasil E-mail: marcosbm@unipam.edu.br

\begin{abstract}
Resumo
Este estudo objetivou avaliar o consumo de bebidas alcoólicas e de tabaco entre alunos do curso de Odontologia do Centro Universitário de Patos de Minas - UNIPAM. Trata-se de um estudo de interferência observacional, transversal, com amostra não probabilística intencional. O questionário foi aplicado à 165 alunos, 40 alunos do gênero masculino e 125 do gênero feminino com idade média de 21,45 anos. Os dados revelaram baixa prevalência de consumo de álcool entre os participantes, cerca de $22 \%$ dos alunos nunca beberam. Dentre aqueles que faziam o consumo de álcool, a maioria consumia de 2 a 4 vezes por semana; nos últimos 12 meses não passou por um episódio de não conseguir parar de beber; não fez consumo matinal de álcool; nunca perdeu alguma função; não teve amnésia alcoólica; não gerou prejuízos a terceiros por causa do uso bebida alcoólica. Uma minoria consome 5 ou mais doses de bebidas alcoólicas em uma única ocasião e confirma sentir culpa ou remorso pela ingestão de bebidas alcoólicas nos últimos 12 meses. A maioria dos alunos nunca fumou um cigarro. Entre a minoria que fuma, a maioria revela ter sido influenciada por colegas; afirma ter usado cigarros nas instalações da universidade; e, no último mês, ainda fez uso de tabaco para mascar, rapé, narguilé, charutos e cachimbos. Nenhuma diferença estatística, quanto ao consumo de álcool e tabaco foi percebida entre os diferentes períodos dos cursos de Odontologia avaliados.
\end{abstract}

Palavras-chave: Álcool; Consumo; Odontologia; Tabaco.

\begin{abstract}
This study aimed to evaluate the consumption of alcoholic beverages and tobacco among students of the Dentistry course at the University Center of Patos de Minas - UNIPAM. This is an observational, cross-sectional interference study, with an intentional non-probabilistic sample. The questionnaire was applied to 165 students, 40 males and 125 females with an average age of 21.45 years. The data revealed a low prevalence of alcohol consumption among the participants, around $22 \%$ of the students had never drank. Among those who consumed alcohol, most consumed it 2 to 4 times a week, in the last 12 months they did not experience an episode of not being able to stop drinking, did not consume alcohol in the morning, never lost any function, no had alcoholic amnesia, did not cause harm to third parties due to the use of alcoholic beverages. A minority consumes 5 or more doses of alcoholic beverages on a single occasion and confirms feeling guilty or remorseful for drinking alcoholic beverages in the last 12 months. Most students have never smoked a cigarette. Among the minority who smoke, the majority reveals having been influenced by colleagues, claims to have used cigarettes on the university premises, and, in the last month, even used tobacco for chewing, snuff, hookah pipe, cigars and pipes. No statistical difference regarding alcohol and tobacco consumption was noticed between the different periods of the evaluated Dentistry courses.
\end{abstract}

Keywords: Alcohol; Consumption; Dentistry; Tobacco. 


\begin{abstract}
Resumen
Este estudio tuvo como objetivo evaluar el consumo de bebidas alcohólicas y tabaco en estudiantes de la carrera de Odontología del Centro Universitario de Patos de Minas - UNIPAM. Se trata de un estudio de interferencia observacional, transversal, con muestra intencional no probabilística. El cuestionario se aplicó a 165 estudiantes, 40 hombres y 125 mujeres con una edad promedio de 21,45 años. Los datos revelaron una baja prevalencia de consumo de alcohol entre los participantes, alrededor del $22 \%$ de los estudiantes nunca había bebido. Entre los que consumieron alcohol, la mayoría lo consumió de 2 a 4 veces por semana, en los últimos 12 meses no experimentaron un episodio de no poder dejar de beber, no consumieron alcohol por la mañana, nunca perdieron ninguna función, no tuvieron amnesia alcohólica, no causó daño a terceros por el uso de bebidas alcohólicas. Una minoría consume 5 o más dosis de bebidas alcohólicas en una sola ocasión y confirma sentirse culpable o arrepentido por beber bebidas alcohólicas en los últimos 12 meses. La mayoría de los estudiantes nunca han fumado un cigarrillo. Entre la minoría que fuma, la mayoría revela haber sido influenciada por colegas, afirma haber consumido cigarrillos en las instalaciones de la universidad, y, en el último mes, incluso consumió tabaco para mascar, rapé, pipa de narguile, puros y pipas. No se notó diferencia estadística en cuanto al consumo de alcohol y tabaco entre los diferentes períodos de los cursos de Odontología evaluados.
\end{abstract}

Palabras clave: Alcohol; Consumo; Odontología; Tabaco.

\title{
1. Introdução
}

O consumo de bebidas alcoólicas e de tabaco é um hábito comum na vida dos acadêmicos de odontologia. Vários são os fatores etiológicos associados a esse fenômeno, dentre eles, destacam-se, o estresse relacionado a vida pessoal e acadêmica, sendo que a estimulação para o consumo de bebidas alcoólicas e tabagismo, em ambientes festivos, é uma constante no ambiente de convívio desses estudantes. A ingestão e uso, tanto de bebidas como de tabaco, trazem grandes prejuízos para a saúde das pessoas, merecendo destaque os efeitos físicos, psíquicos e sociais (Lima et al., 2020).

O tabagismo e alcoolismo são identificados como grandes fatores de risco para doenças odontológicas, como: xerostomia, doença periodontal, halitose e possuem um importante papel na carcinogênese para diferentes neoplasias da cavidade bucal, atuando como agentes promotores. O uso de bebidas alcoólicas potencializa substancialmente a ação do tabaco no processo de tumorogênese da mucosa bucal (Leite et al., 2021).

É inegável que a utilização de álcool e tabaco em fases precoces da vida pode acarretar aos usuários diversos danos físicos relacionados com acidentes de trânsito, violência, prática sexual desprotegida e até mesmo consumo de drogas ilícitas. O próprio consumo desenfreado dessas substâncias está relacionado com aumento do índice de depressão e ansiedade (Silva e Romarco, 2021).

Apesar do acadêmico de odontologia ter conhecimento acerca das mazelas sistêmicas e agravos em saúde bucal que o tabaco e álcool podem acarretar desde a indução do câncer bucal ao impacto deletério da pigmentação exógena dentária associada, diversos trabalhos, com esse público específico de estudante, têm demonstrado um alto consumo, tanto do álcool quanto do tabaco, em meio a esses alunos (Montes et al., 2015). Isso reforça que apenas ter conhecimento não é suficiente para a modificação de hábitos individuais, por isso, a realização de estudos com o objetivo de reconhecer o perfil de consumo, tanto do álcool quanto do tabaco, dentre esse público específico de jovens se justifica, para que se possa pensar em ações especificas a cerca dessa problemática.

O consumo de álcool e tabaco entre universitários no Brasil é uma realidade. Pensou-se que com o curso de Odontologia não seria diferente, já que a transição do Ensino Médio para o Ensino Superior, pode trazer uma pressão autoimposta na busca de resultados satisfatórios na vida acadêmica, visando resultados profissionais futuros (Ham \& Hope, 2003, Rizzieri \& Afonso, 2011).

Nesse sentido, partiu-se para responder a seguinte indagação: Como se estabelece o consumo de bebidas alcoólicas e tabaco entre acadêmicos do curso de Odontologia do Centro Universitário de Patos de Minas - Unipam? Partiu-se do pressuposto de que fosse elevado, mas essa hipótese foi refutada, assim como é possível verificar ao longo dos resultados do presente estudo. 
O meio acadêmico parece levar estudantes de Odontologia a um contato maior com as substâncias psicoativas, por vezes, com o intuito de aliviar estresse e tensões emocionais evidentemente que o meio universitário é permeado de diversos aprendizados, porém, esse espaço pode ainda suscitar fatores motivacionais para o consumo de álcool e tabaco. Por isso, ressalta-se a necessidade de estudar os comportamentos que possam levar riscos à saúde de universitários.

O objetivo geral deste estudo foi avaliar o consumo de bebidas alcoólicas e de tabaco em alunos do curso de Odontologia do Centro Universitário de Patos de Minas - UNIPAM.

\section{Metodologia}

A fim de alcançar os objetivos proposto neste trabalho, a originalidade do estudo foi primária, de interferência observacional, com período de seguimento transversal, constituído por uma amostra não probabilística intencional ou de conveniência. O perfil de avaliação analítica teve abordagem qualitativa e quantitativa controlada para os acadêmicos pesquisados. A procedência da equipe de pesquisa do estudo foi de centro único participante.

O presente artigo foi submetido ao Comitê de Ética e Pesquisa (CEP) do Centro Universitário de Patos de Minas e, após aprovação e autorização, o estudo foi realizado. Todos participantes matriculados no curso de odontologia do Centro Universitário de Patos de Minas - UNIPAM, foram informados sobre os objetivos do estudo, devendo ter concordado e assinado o Termo de Consentimento Livre e Esclarecido - TCLE e/ou Termo de Assentimento Livre e esclarecido TALE.

Todas as medidas de prevenção sanitária para COVID-19 foram adotadas em todas as atividades de pesquisa, de forma a minimizar prejuízos e potenciais riscos, além de prover cuidado e preservar a integridade e assistência dos participantes e da equipe de pesquisa, conforme preconizado pelo ofício circular $\mathrm{N}^{\circ}$ 16/2020/CONEP/SECNS/MS .

A amostra foi constituída por discentes do Curso de Odontologia do UNIPAM, matriculados no segundo semestre de 2021. Atualmente, a população de alunos de Odontologia matriculados, no primeiro semestre de 2021 na instituição, é de 240 acadêmicos, estando 39 destes no primeiro período, 30 no terceiro, 49 no quinto, 37 no sétimo, 55 no nono e 30 no décimo período. Como a turma do décimo período se tornou egressa a partir de julho de 2021, a mesma não participou da pesquisa. O grupo amostral, portanto, foi constituído por 210 acadêmicos de Odontologia atualmente matriculados no curso.

$\mathrm{O}$ estudo foi realizado nos ambientes institucionais frequentados pelos alunos do curso de Odontologia do Centro Universitário de Patos de Minas e no Centro Clínico Odontológico - UNIPAM. A amostra foi dimensionada por meio de critérios de inclusão e exclusão. Dessa forma, participaram desse artigo alunos do Curso de Odontologia regularmente matriculados, maiores de idade que concordarem em participar da pesquisa. Os alunos menores de idade foram incluídos mediante assinatura do Termo de Assentimento Livre e Esclarecido - TALE pelo próprio aluno e do TCLE assinado pelo pai ou responsável.

O pesquisador principal responsável pelo artigo e os demais envolvidos, assumiram a responsabilidade de manter a confiabilidade e sigilo de todas as informações obtidas, preservando sempre a identidade do paciente. A identidade do participante da pesquisa ficará de forma integral preservada, evitando qualquer forma de constrangimento, conforme a resolução 466/12.

Foi utilizado o questionário AUDIT composto por 10 questões de maneira adaptada ao questionário sobre consumo de tabaco. O AUDIT foi desenvolvido pela OMS (Organização Mundial de Saúde) baseando-se em estudos conduzidos na Austrália, Quênia, Noruega, Bulgária, México e Estados Unidos (Saunders, 1993). A versão em português brasileira do AUDIT foi proposta por Mendéz (1999) e, posteriormente, validada por Lima et al., (2005). O AUDIT é um instrumento que avalia problemas associados ao consumo de álcool e detecta o padrão de consumo de risco. As três primeiras questões do questionário permitiram estimar o uso de álcool e as demais mensuraram as consequências relacionadas ao consumo. As pontuações do AUDIT se correlacionam positivamente com as medidas de consequências do consumo, alterações de 
comportamento, vulnerabilidade à dependência de álcool e estados de ânimo negativos. O escore obtido no questionário AUDIT classifica o paciente em: baixo risco ou abstêmio (até 7 pontos), usuário de risco (de 8 a 15 pontos), uso nocivo (de 16 a 19 pontos) e dependência química (acima de 20 pontos). Os resultados obtidos com a aplicação dessas dez primeiras questões relativas ao questionário AUDIT geraram variáveis ordinais que permitiram a comparação entre os grupos analisados.

Foi utilizada uma adaptação da Global Health Professional Students Survey (GHPSS) para as sete perguntas finais do questionário aplicado aos discentes. A Pesquisa Mundial sobre Tabagismo em Adultos (Global Adult Tobacco Survey GATS) foi desenvolvida para produzir estimativas nacionais e subnacionais, para a população adulta dos países, sobre consumo de tabaco, exposição passiva à fumaça de tabaco, tentativas para deixar de fumar, além de medir indiretamente o impacto de diversas iniciativas para o controle e a prevenção do tabagismo em âmbito nacional.

A GATS, um componente do Sistema Mundial de Vigilância de Tabagismo (Global Tobacco Surveillance System GTSS), tem como objetivo melhorar a capacidade dos países de planejamento, execução e avaliação dos programas para controle e prevenção do tabagismo. O GTSS monitora o consumo de tabaco e as medidas para controle do tabagismo. Além da GATS, o GTSS é composto de três pesquisas de base escolar em jovens e em população adulta selecionada: a Pesquisa Mundial sobre Tabagismo em Jovens (Global Youth Tobacco Survey - GYTS), a Pesquisa Mundial sobre Tabagismo em Profissionais Escolares (Global School Personnel Survey - GSPS) e a Pesquisa Mundial sobre Tabagismo em Estudantes de Profissões de Saúde (Global Health Professional Students Survey - GHPSS). (Grupo Colaborativo para a Pesquisa Mundial Sobre Tabagismo em Adultos, 2011). Os resultados obtidos com a aplicação dessas sete últimas questões relativas à adaptação do questionário GHPSS geraram variáveis ordinais que permitiram a comparação entre os grupos analisados.

Uma estatística descritiva e analítica dos dados foi realizada acerca dos diferentes questionamentos levantados pelos questionários. Para a análise das respostas, os alunos foram alocados em cinco diferentes grupos de acordo com o ano em que estiverem matriculados no curso de Odontologia do UNIPAM. Os grupos foram comparados em busca de diferença estatisticamente significante a partir de variáveis ordinais (obtidas pela aplicação do questionário), sendo que o teste estatístico Kruskal Wallis foi utilizado para análise comparativa das variáveis ordinais entre os grupos alocados. O teste KrusKal-Wallis tem por objetivo a comparação de três grupos ou mais de amostras não pareadas. Os dados epidemiográficos gerados foram analisadas por meio de estatística descritiva de frequência e dispersão (média, mediana e desvio padrão das respostas geradas). O nível de significância foi estabilizado em 5\%. As análises foram realizadas por meio do software GraphPad Prism (San Diego, Califórnia - USA).

\section{Resultados}

\subsection{Perfil dos alunos}

Este estudo epidemiológico observacional transversal permitiu a evidenciação, por meio de uma análise qualitativa e quantitativa, dos seguintes resultados: Uma população de 210 alunos do curso de Odontologia do Centro Universitário de Patos de Minas foi abordada para participação neste estudo. O questionário foi aplicado, por meio de entrevistas individuais, para 165 alunos do curso de Odontologia do Centro Universitário de Patos de Minas, o que configurou um índice de participação da ordem de 78,57\%. Com relação ao perfil epidemiográfico dos participantes, 40 alunos eram do sexo masculino, o que corresponde a 24,24\% do grupo amostral; 125 alunos eram do sexo feminino, o que corresponde a 75,76\% da amostra. A idade média dos participantes foi de: 21,45 anos. O grupo amostral contou com a participação de 32 alunos do segundo período do curso, 29 alunos do quarto período do curso, 22 alunos do sexto período do curso, 34 alunos do oitavo período do curso e 48 alunos do décimo período do curso de Odontologia. De acordo com a matriz curricular do curso de Odontologia do UNIPAM, os alunos do segundo período encontram-se em ciclo básico do curso; os alunos do quarto período estão no ciclo pré-clínico e os alunos do sexto, oitavo e décimo períodos vivenciam de maneira rotineira o ciclo de aprendizagem clínico. 


\subsection{Consumo de bebidas alcoólicas}

O Gráfico 1 relaciona o consumo (frequência semanal) de bebidas alcoólicas e as frequências semanais de consumo relativas.

Gráfico 1: Frequência consumo bebidas alcoólicas.

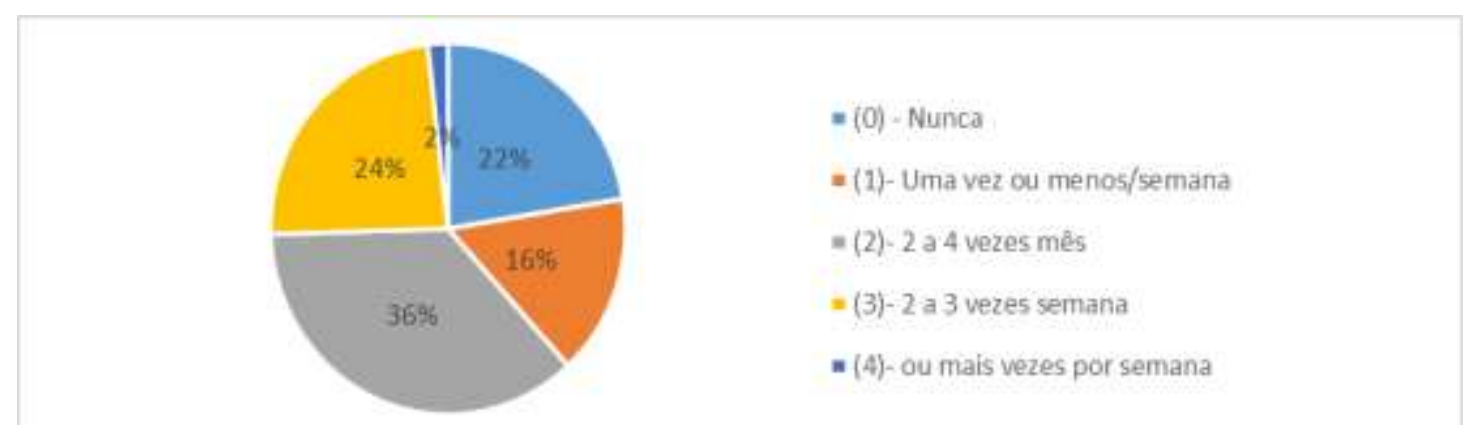

Fonte: Autores (2021).

O Gráfico 1 mostra que a maior parte dos alunos 36\% consume bebidas alcoólicas de 2 a 4 vezes por semana. Nota-se que apenas $2 \%$ da amostra consume bebidas alcoólicas 4 ou mais vezes por semana, e cerca de $22 \%$ nunca consumiu essa substância. O Gráfico 2 tem relação com o número de doses de bebidas alcoólicas consumidas em um dia normal.

Gráfico 2: Número de doses / dia normal.

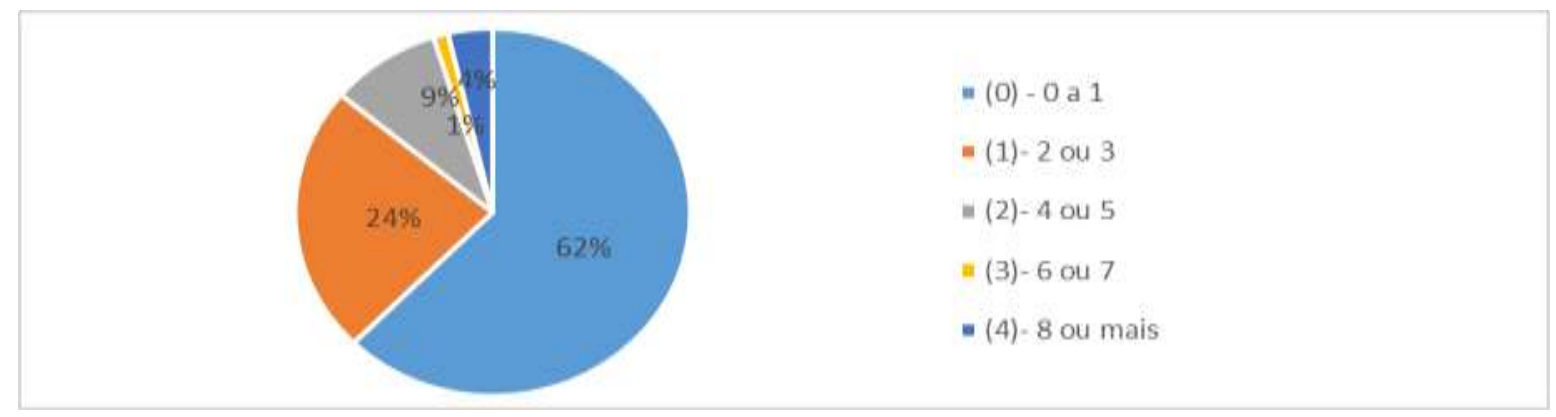

Fonte: Autores (2021).

O Gráfico 2 revela que 62\%, a maioria de alunos, consomem de 0 a 1 dose de bebidas alcoólicas em um dia normal, mas, 24\% revelou consumir 2 ou 3 doses diárias. O Gráfico 3 mostra a frequência de ingestão de cinco ou mais doses de bebidas alcoólicas em uma única ocasião.

Gráfico 3: Frequência do consumo de 5 ou mais doses por ocasião.

$\begin{aligned} & =(0) \text { - Nunca } \\ & =(1) \text { - Pelo menos uma vez semana } \\ & =(2) \text { - Uma vez por mês } \\ & =(3) \text { - Uma vez semana } \\ & =(4) \text { - Quase todos dias }\end{aligned}$

Fonte: Autores (2021). 
O Gráfico 3 mostra que apenas $1 \%$ da amostra consome 5 ou mais doses de bebidas alcoólicas em uma única ocasião. Com relação a frequência da capacidade de interromper o uso de bebidas alcoólicas, uma vez tendo começado a ingerir, nos últimos 12 meses, os seguintes resultados foram encontrados, conforme o Gráfico 4:

Gráfico 4: Frequência de não conseguir parar de beber uma vez tendo começado nos últimos 12 meses.

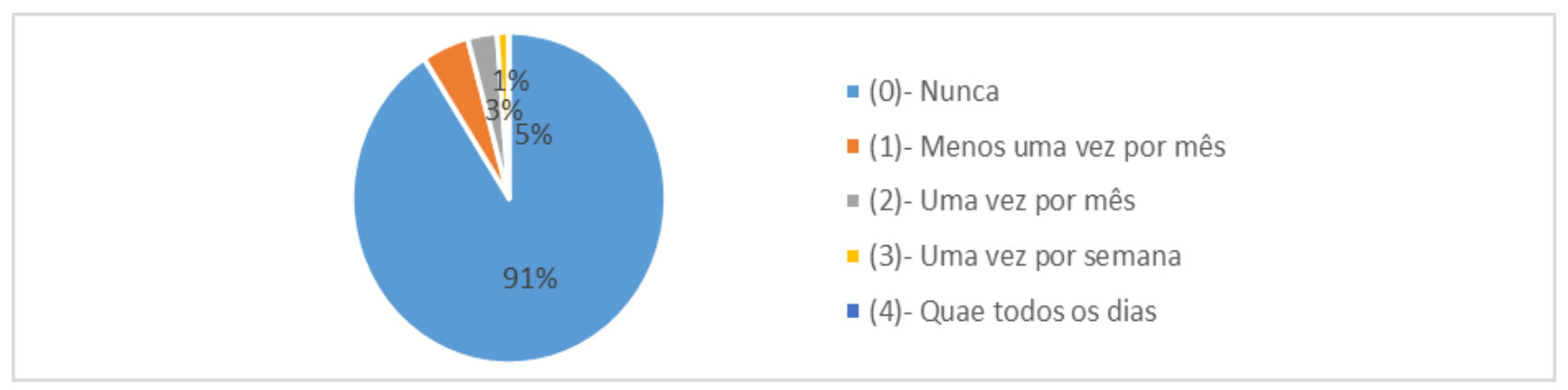

Fonte: Autores (2021).

Em presença dos resultados do Gráfico 4, observa-se que a maioria, 91\%, nunca passou por um episódio de não conseguir parar de beber tendo começado nos últimos 12 meses. Com relação a frequência da perda de função devido ao consumo de bebidas alcoólicas nos últimos 12 meses, as seguintes frequências relativas foram obtidas junto aos participantes e são apresentadas no Gráfico 5:

Gráfico 5: Frequência da perda de função em razão do consumo de álcool nos últimos 12 meses.

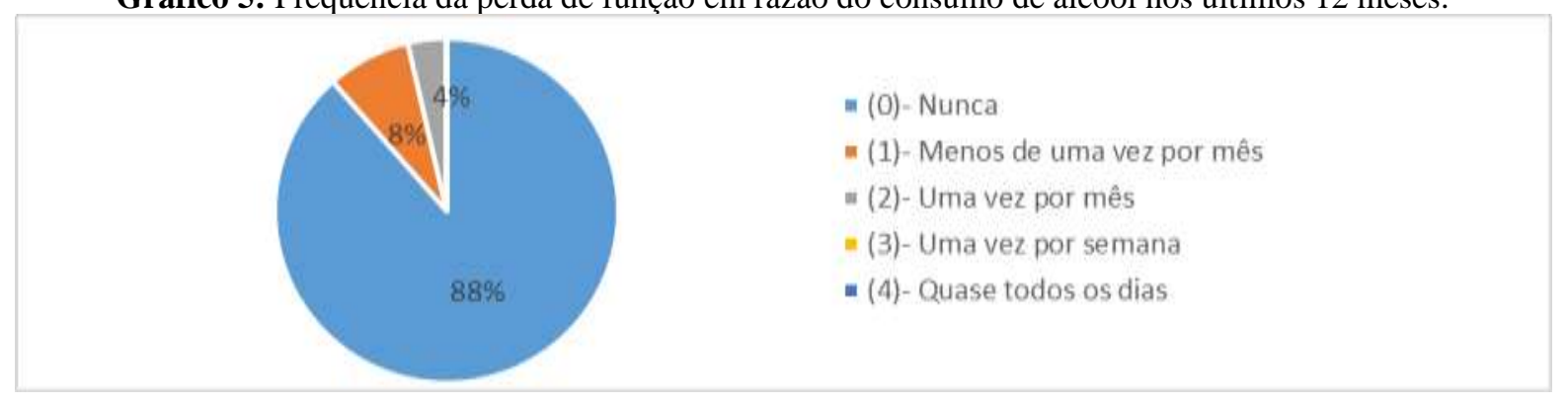

Fonte: Autores (2021).

Diante dos dados evidenciados no gráfico 5, certifica-se que a maioria, 88\%, dos alunos nunca passou por perda de função devido ao consumo de álcool. Alusivo a frequência da ingestão matinal de bebidas alcoólicas após a ingestão intensa no dia anterior, nos últimos 12 meses, as seguintes frequências relativas foram obtidas junto aos participantes e apresentadas no Gráfico 6:

Gráfico 6: Frequência do consumo matinal de álcool nos últimos 12 meses.

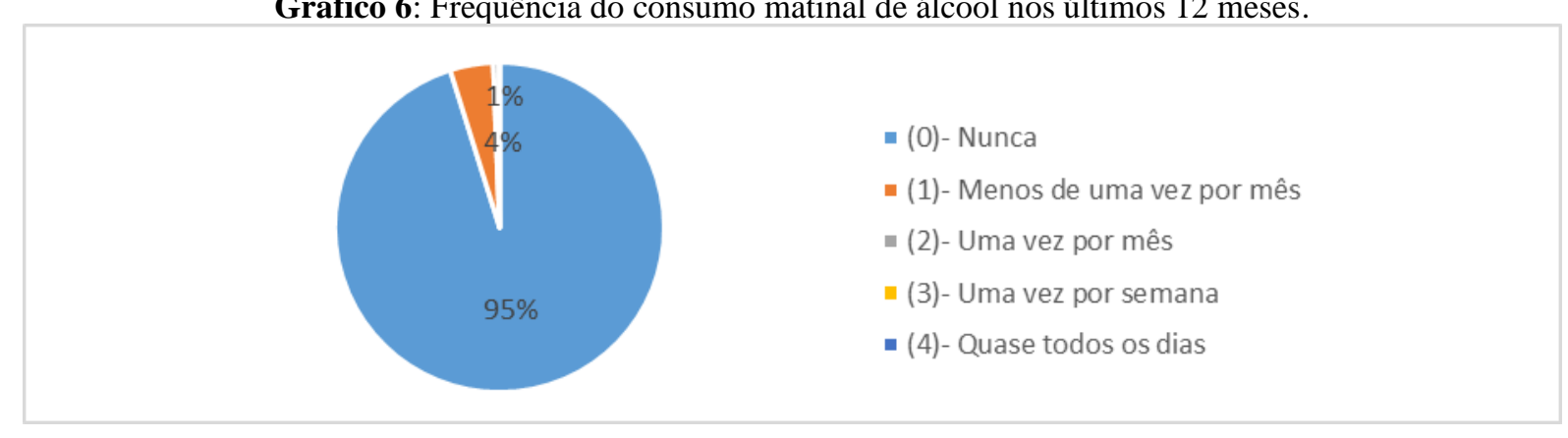

Fonte: Autores (2021). 
O gráfico 6 revela que a maioria, 95\%, dos alunos nunca fez consumo matinal de álcool nos últimos 12 meses. Com relação a frequência de culpa ou remorso pela ingestão de bebida alcoólicas nos últimos 12 meses, as seguintes frequências relativas foram obtidas junto aos participantes e apresentadas no Gráfico 7:

Gráfico 7: Frequência de culpa/remorso nos últimos 12 meses pelo uso de bebidas.

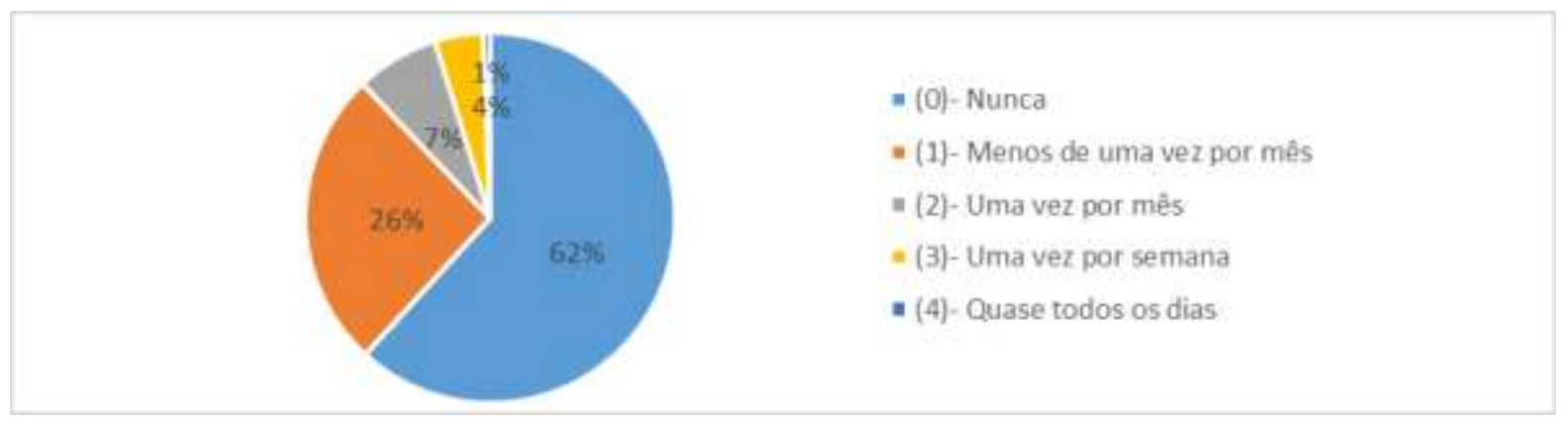

Fonte: Autores (2021).

Com relação a frequência de culpa ou remorso pela ingestão de bebidas alcoólicas, nos últimos 12 meses, a maioria, $62 \%$, dos alunos revelaram não ter esse sentimento. Mas, um percentual importante de $26 \%$ da amostra revelou que sentiu culpa ou remorso menos de uma vez por mês. Apenas $1 \%$ dos alunos afirmou ter tido culpa/remorso uma vez por semana. Referente à frequência de amnésia alcoólica nos últimos 12 meses, as seguintes frequências relativas foram obtidas junto aos participantes, segundo o Gráfico 8:

Gráfico 8: Frequência de amnésia alcoólica nos últimos 12 meses.

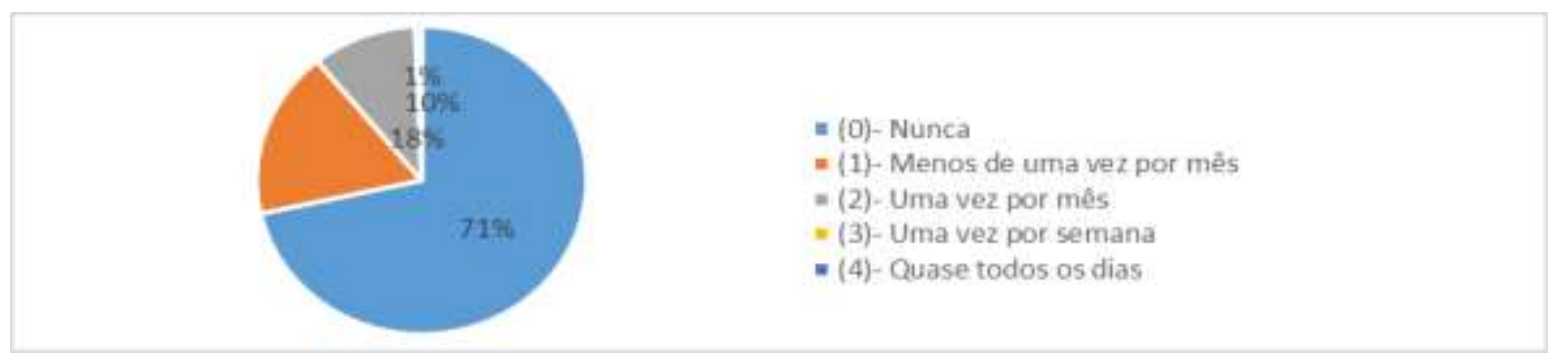

Fonte: Autores (2021).

Com relação a frequência de amnésia alcoólica, nos últimos 12 meses, a maioria, 71\%, dos alunos revelou nunca ter tido episódios dessa natureza, enquanto que $18 / \%$ citou ocorrer menos de uma vez por mês, outros $10 \%$ uma vez por mês e apenas $1 \%$ dos alunos uma vez por semana. Sobre a frequência de prejuízos ou danos a terceiros devido a ingestão de bebidas alcoólicas, as seguintes frequências relativas foram obtidas junto aos participantes conforme o Gráfico 9:

Gráfico 9: Frequência de prejuízos a si próprio ou terceiros pelo uso de bebidas.

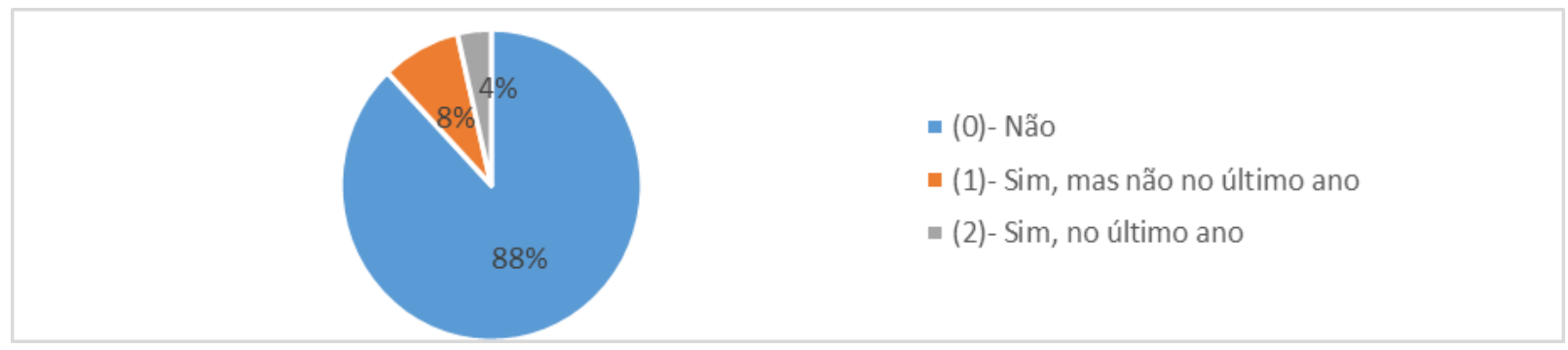

Fonte: Autores (2021). 
Com relação a frequência de prejuízos ou danos a terceiros devido a ingestão de bebidas alcoólicas, a maioria, 88\%, dos alunos revelou não gerar prejuízos a si próprios ou a terceiros pelo uso de bebidas alcoólicas. Cerca de $8 \%$ dos alunos já alegaram esse episódio, mas, não no último ano e $4 \%$ dos alunos afirmaram ocorrer prejuízos pelo uso de bebidas alcoólicas. Com relação a frequência com que algum parente, amigo ou médico, já havia se preocupado com o fato do aluno beber ou de sugerir que parasse de beber, as seguintes frequências relativas foram obtidas junto aos participantes e são mostradas no Gráfico 10:

Gráfico 10: Frequência da preocupação de terceiros com o uso de bebidas alcoólicas.

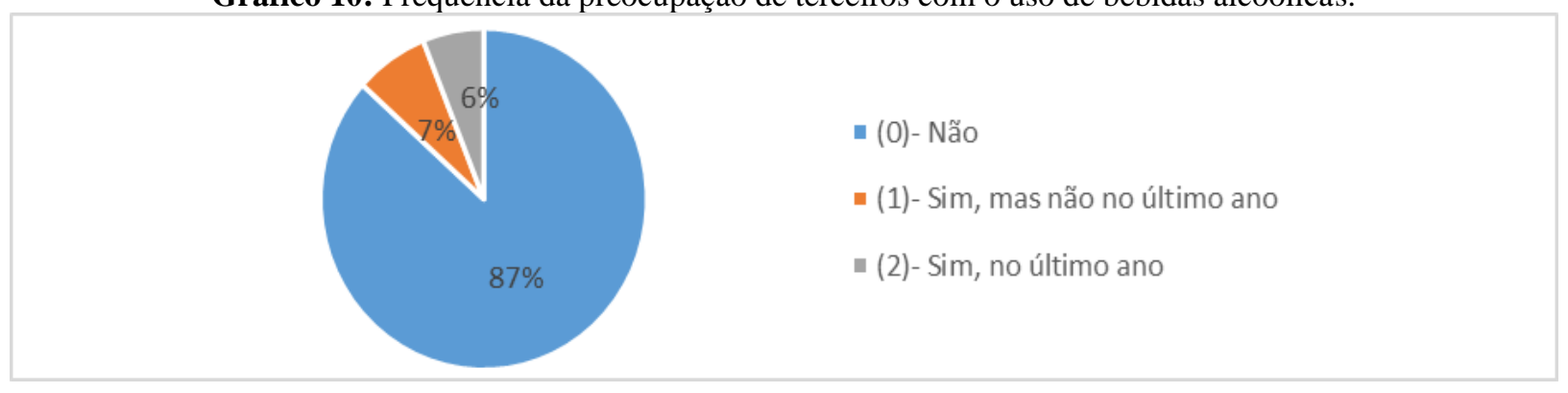

Fonte: Autores (2021).

Com relação a frequência com que algum parente, amigo ou médico, já havia se preocupado com o fato de você beber ou de sugerir que você parasse de beber, o Gráfico 10 sinaliza que a maior parte de $87 \%$ não confirma esse acontecimento. Outros $7 \%$ revela que sim, mas, não no último ano. E, os demais de $6 \%$ citaram que sim no último ano.

\subsection{Consumo de tabaco}

Com relação a frequência de idades quando da utilização inicial de cigarro, as seguintes frequências relativas foram obtidas junto aos participantes, conforme Gráfico 11.

Gráfico 11: Frequência de idades relacionadas ao uso inicial de cigarro.

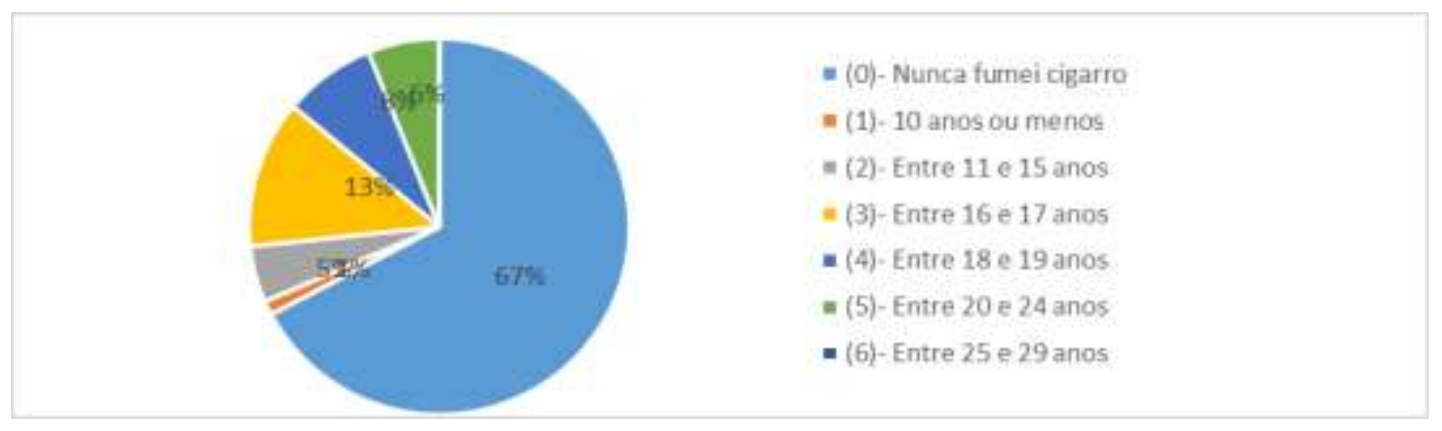

Fonte: Autores (2021).

Com relação a frequência de idades quando da utilização inicial de cigarro, a maioria, 67\%, dos alunos revelou nunca ter fumado um cigarro. Mas, $13 \%$ dos alunos confirmaram que começaram a fumar entre 16 e 17 anos, $8 \%$ entre 18 e 19 anos, $5 \%$ entre 11 e 15 anos, e apenas $1 \%$ revelou ter 10 anos ou menos. Com relação a frequência de modalidades de influência para o uso de cigarros, as seguintes frequências relativas foram obtidas junto aos participantes: 
Gráfico 12: Frequência de modalidades de influências associadas ao início do hábito de fumar.

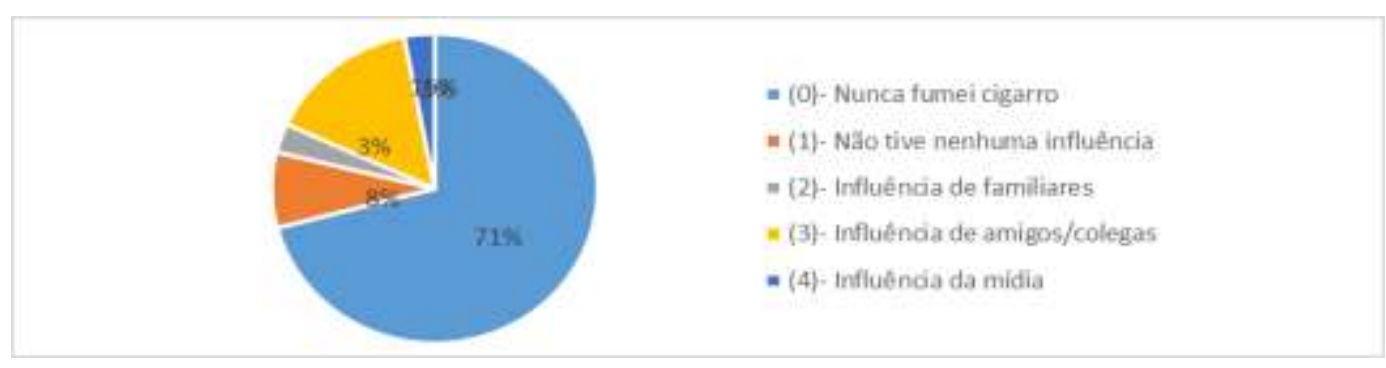

Fonte: Autores (2021).

Conforme o gráfico 12 , cerca de $15 \%$ dos alunos revelaram terem sido influenciados por amigos e colegas, $8 \%$ afirmaram nunca terem tido influência para fumar, 3\% mencionaram terem tido a influência de familiares e 3\% disseram ter recebido influência de mídia. Com relação à frequência de números de dias utilizando cigarros durante um mês, as seguintes frequências relativas foram obtidas junto aos participantes e apresentadas no Gráfico 13:

Gráfico 13: Frequência de dias de utilização de cigarros no último mês.

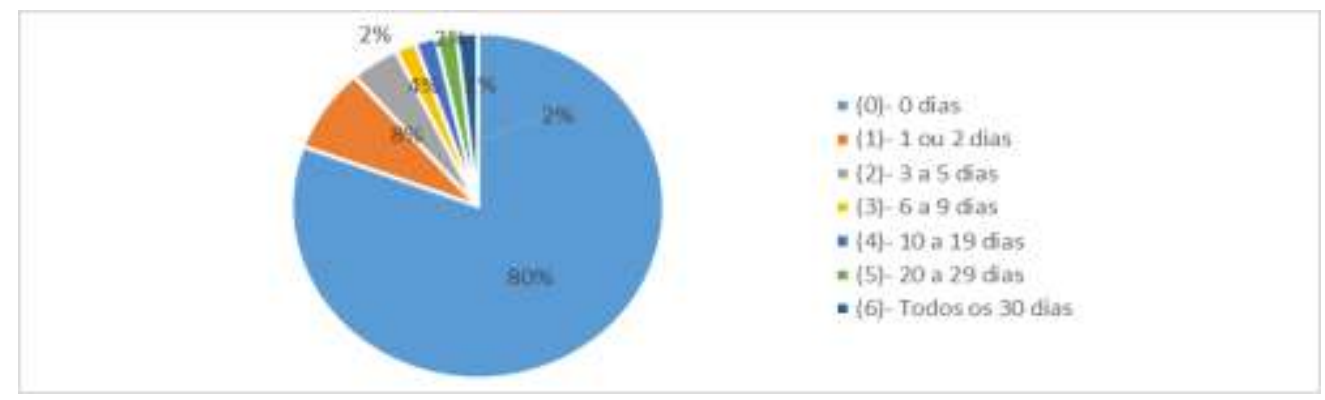

Fonte: Autores (2021).

De acordo com o Gráfico 13 a maioria, 80\%, dos alunos não é fumante, como visto nos gráficos anteriores. Mas, cerca de $8 \%$ fumou entre 1 e 2 dias, outros $4 \%$ entre 3 e 5 dias, $2 \%$ entre 10 e 19 dias e os demais $2 \%$ entre 20 e 29 dias. Durante todos os 30 dias, apenas $2 \%$ dos alunos reportaram tal consumo intenso. Com relação a frequência de utilização de cigarros nas instalações/propriedades da universidade, as seguintes frequências relativas foram obtidas junto aos participantes e expressas no Gráfico 14:

Gráfico 14: Frequência da utilização de cigarros na instituição.

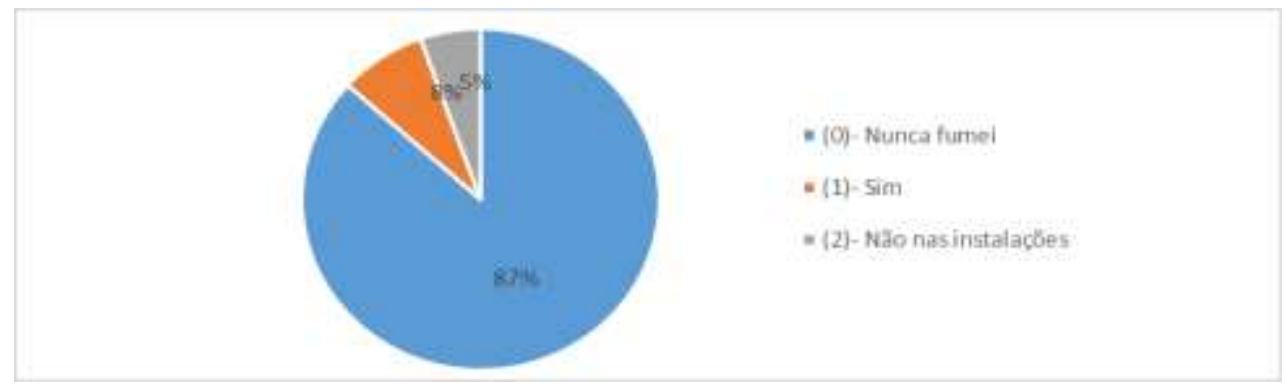

Fonte: Autores (2021).

O Gráfico 14 mostra que com relação a frequência de utilização de cigarros nas instalações/propriedades da universidade, $8 \%$ afirma que faz uso do tabaco nesses locais, e outros $5 \%$ revela que não nas instalações da Universidade. Com 
relação a frequência de uso de tabaco para mascar, rapé, narguilé, charutos ou cachimbos, as seguintes frequências relativas foram obtidas junto aos participantes e apresentadas no Gráfico 15:

Gráfico 15: Frequência de uso de tabaco para mascar, rapé, narguilé, charutos ou cachimbos.

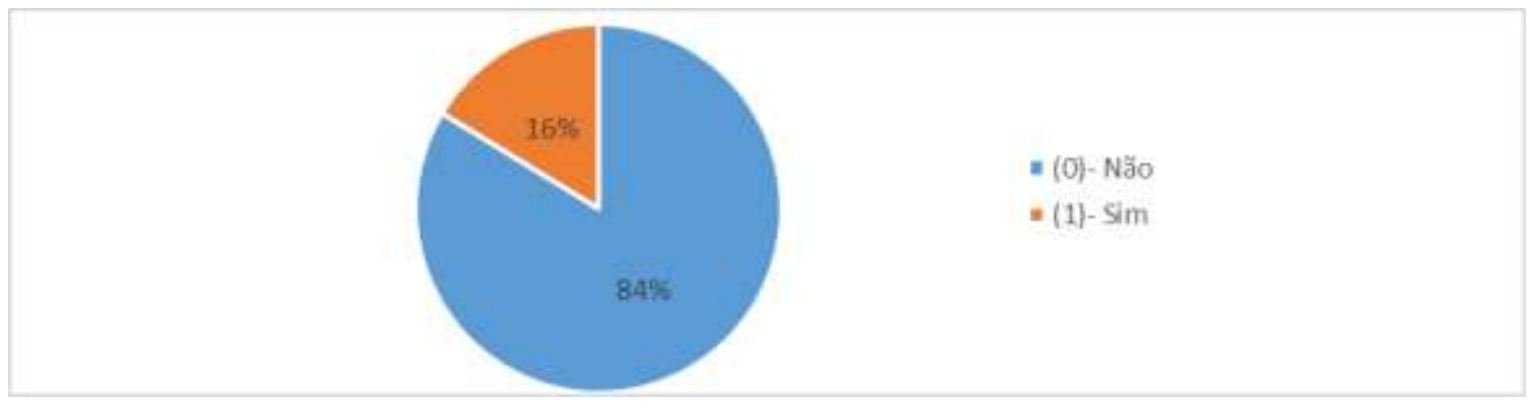

Fonte: Autores (2021).

Conforme o Gráfico 15, $16 \%$ dos alunos fazem uso de tabaco para mascar, rapé, narguilé, charutos ou cachimbos. A frequência de números de dias em que foi utilizado tabaco para mascar, rapé, narguilé, charutos ou cachimbos durante o último mês é apresentada no Gráfico 16:

Gráfico 16: Frequência do uso de tabaco para mascar, rapé, narguilé, charutos ou cachimbos no último mês.

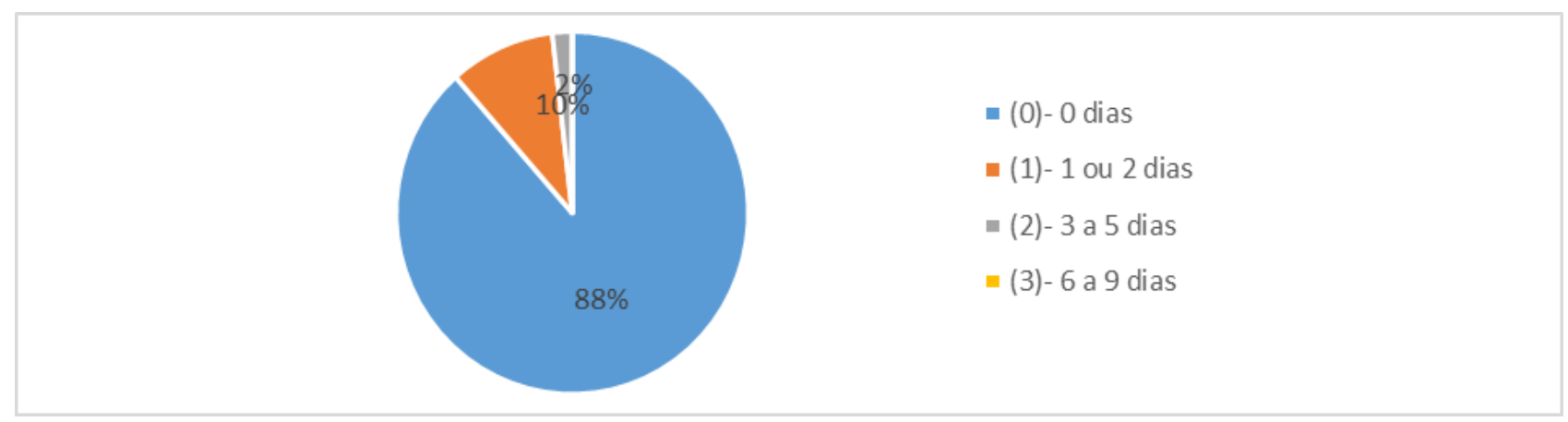

Fonte: Autores (2021).

A frequência de números de dias em que foi utilizado tabaco para mascar, rapé, narguilé, charutos ou cachimbos durante o último mês, foi de cerca de $10 \%$. A frequência de uso de tabaco para mascar, rapé, narguilé, charutos ou cachimbos nas instalações/propriedades da instituição, é mostrada no Gráfico 17:

Gráfico 17: Frequência do uso de tabaco de mascar, rapé, narguilé, charutos ou cachimbos na instituição.

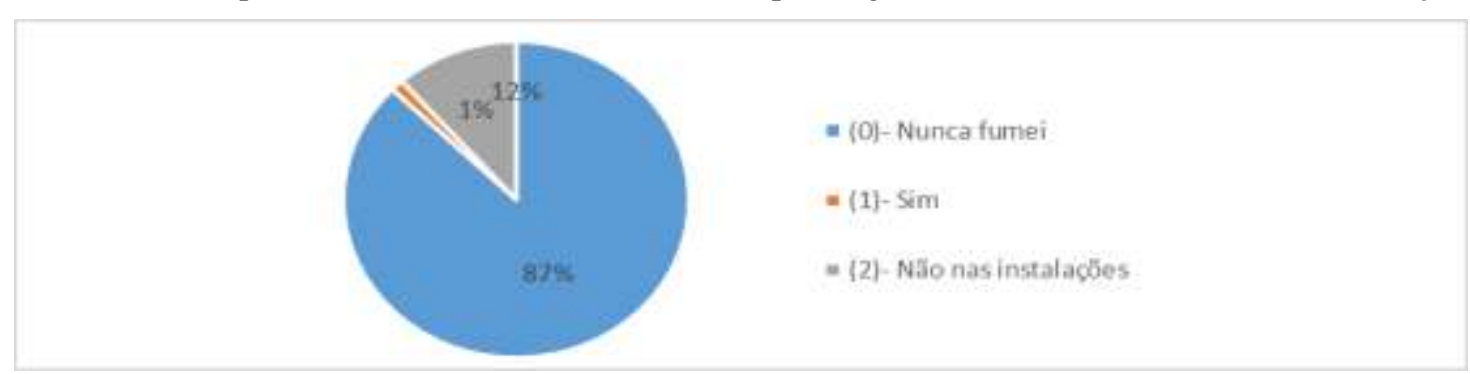

Fonte: Autores (2021). 
O Gráfico 17 revela que $12 \%$ dos alunos fizeram uso de tabaco para mascar, rapé, narguilé, charutos ou cachimbos fora das instalações institucionais e, apenas, $1 \%$ o fizeram na própria instituição.

Referente a interferência do momento do desenvolvimento acadêmico dos alunos de acordo com os períodos (segundo, quarto, sexto, oitavo e décimo) do curso de odontologia e as variáveis analisadas, nenhuma diferença estatística entre os grupos foi percebida em todas as análises, como se observa nos gráficos seguintes:

Gráfico 18:
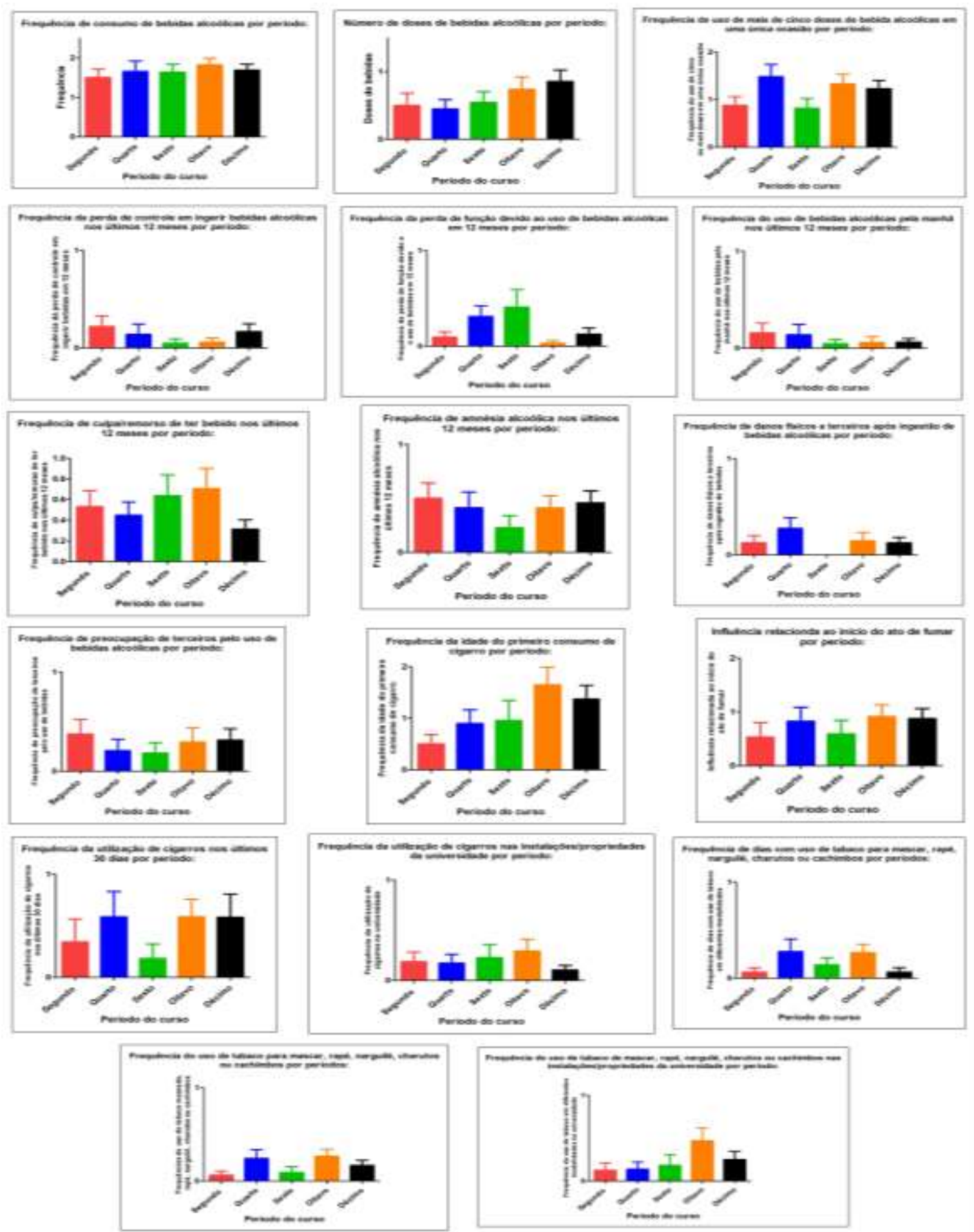

Fonte: Elaborado pelos autores (Análise estatística realizada por meio do teste estatístico KrusKal Wallis em que se observa ausência de diferença estatística entre os grupos, $\mathrm{p}>0,05$ ). 


\section{Discussão}

O uso de drogas como álcool é um problema de saúde pública e representa um grande desafio para o sistema de saúde brasileiro. Nos últimos anos, no Brasil e no mundo, o consumo dessa substância vem aumentando expressivamente. Cada vez mais é imprescindível que os profissionais de saúde junto a sociedade estejam prontos para lidar com esse comportamento. Conforme a "United Nations Office on Drugs and Crime no ano de 2016 estimou-se que cerca de 275 milhões de pessoas, com idade de 15 a 64 anos, utilizaram algum tipo de droga, seja lícita ou ilícita" (Rodrigues et al., 2021, p.5354).

Opostamente ao cenário mundial, o presente estudo revelou baixa prevalência do consumo de álcool entre os estudantes de Odontologia do Centro Universitários de Patos de Minas - UNIPAM. Pois, cerca de 22\% dos alunos nunca beberam, realidade esta muito benéfica para esses participantes, isso porque o álcool ou etanol é uma substância psicoativa que causa intoxicação em diversos órgãos do corpo, pois é, imunossupressora, carcinogênica, teratogênica, cujo uso frequente conduz a dependência química (Monteiro, 2020).

Importante destacar que o meio acadêmico pode vir a ser um ambiente para motivar o consumo do álcool entre os jovens (Wagner e Andrade, 2008), pois este pode vir acompanhado de: "curiosidade, aceitação e estímulo pelos pares, desinibição, melhora da sociabilidade, diminuição da ansiedade e estresse gerados pela escola, trabalho e família" (Pennachioni et al., 2021). Mas, ao menos no presente estudo, o meio acadêmico não parece ter sido fonte de motivação para despertar a maioria dos alunos para o consumo de álcool. Melhor assim, porque o estudo como de Pillon; Corradi-Webster (2006) corroboram que estudantes universitários que fazem uso problemático de bebidas alcoólicas tendem a não serem pontuais para assistirem aulas e ainda costumam dormir mais em sala de aula no dia posterior a eventos festivos.

No estudo realizado, dentre aqueles alunos que consomem álcool, a maior parte consome de 2 a 4 vezes por semana e de 0 a 1 dose em um dia normal. Mas, conforme Monteiro (2020) qualquer quantidade de álcool se encontra relacionada com algum risco para a saúde, citam-se como, exemplo, a ocorrência do câncer de mama, as lesões físicas traumáticas e a dependência (Monteiro, 2020).

A propósito do gênero dos alunos, o estudo desenvolvido contou com uma amostra de 165 alunos, a maioria (125 alunas) do gênero feminino, o que correspondeu a 75,76\% da amostra. A idade média dos participantes foi de 21,45 anos. Mendonça (2021) explicita com se estabelece o consumo de baixo risco de álcool para homens e mulheres, conforme Quadro 1.

Quadro 1: Consumo baixo risco.

\begin{tabular}{|l|l|}
\hline \multicolumn{1}{|c|}{ Homens } & \multicolumn{1}{c|}{ Mulheres } \\
\hline 2 bebidas padrão/dia & 1 bebidas padrão/dia \\
\hline 14 bebidas padrão/semana & 7 bebidas padrão/semana \\
\hline
\end{tabular}

Fonte: Mendonça (2021, p.5-6)

Mendonça (2021) também realizou, em seu trabalho, uma exposição sobre equivalência de diferentes bebidas alcoólicas em relação a uma unidade de bebida padrão de 10 gr. álcool puro, conforme Figura 1. 
Figura 1: Uma unidade de bebida padrão - 10 gr. álcool puro.

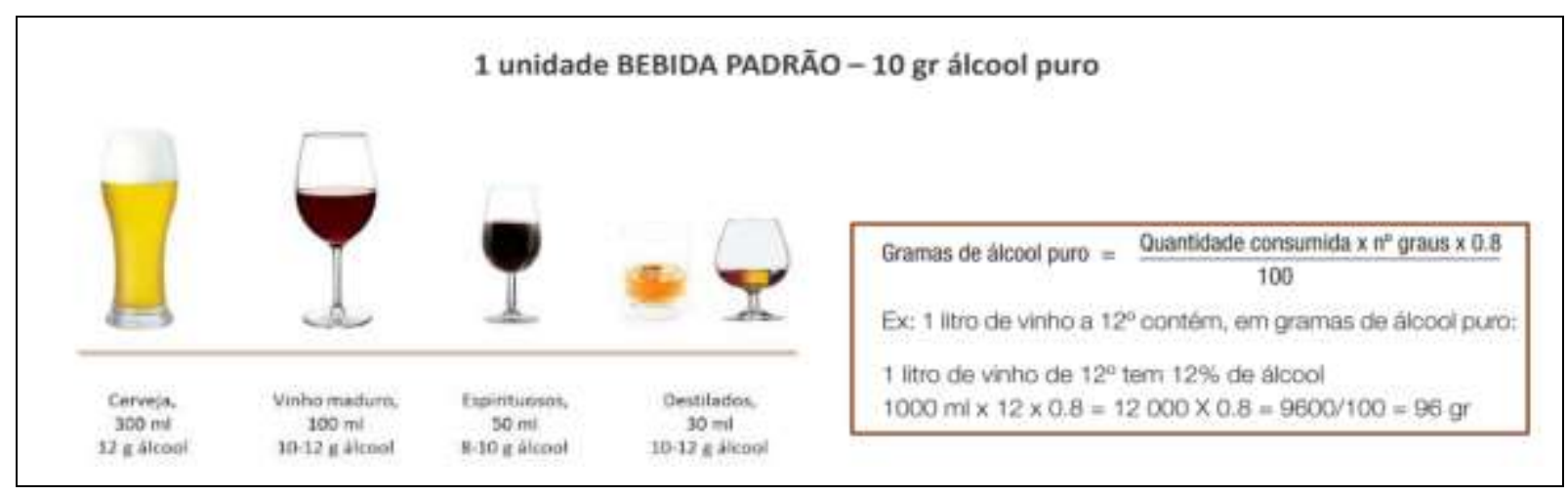

Fonte: Mendonça (2021, p.5-6).

Não existem evidências sobre certo tipo de álcool ser mais maléfico, porém, o fator etiológico mais relevante incide na quantidade de álcool que se consome. Apesar disso, a cerveja e o vinho contribuem para aumentar o risco de desenvolver câncer, sendo que o etanol encontra-se presente em quase todas as bebidas (Leite et al., 2021).

É importante citar que, as ocasiões de consumo excessivo de álcool parecem determinar o risco adverso e os danos subsequentes, ou seja: em sociedades onde a maior parte do álcool é consumida em ocasiões de consumo não pesado, espera-se uma relação geral benéfica do uso do álcool nas doenças isquêmicas e um impacto líquido geral muito pequeno do uso do álcool nas doenças cardiovasculares e mortalidade. Em sociedades onde a maior parte do álcool é consumida em ocasiões de bebedeira, a relação geral deve ser prejudicial para doenças isquêmicas e, ainda mais, para doenças cardiovasculares e morte (Rehm et al., 2017).

O estudo demonstrou que a maioria dos alunos que consome álcool, nos últimos 12 meses, não passou por um episódio de não conseguir parar de beber e, também, não fez consumo matinal de álcool. Entretanto, Ribeiro, Laranjeira e Messas (2013) advertem que "não é necessário ser dependente para apresentar problemas relacionados ao consumo. (...) Nenhum padrão de consumo está isento de riscos". O consumo de álcool em doses baixas e cercado de precauções para prevenir acidentes é um consumo de baixo risco. O consumo quase sempre escoltado de complicações, como brigas, acidentes, perda de compromissos é designado uso nocivo ou abuso. Quando o consumo é frequente, compulsivo, proposto à evitar sintomas de abstinência e acompanhado "por problemas físicos, psicológicos e sociais, fala-se em dependência. (...) O padrão de consumo é influenciado por fatores de proteção e risco. (...) Entre o bebedor social e o dependente há um número incontável de padrões de consumo. " (ibid, p.9). Cada pessoa desenvolve um padrão particular de consumo ao longo da vida, que pode ser influenciado por diversos fatores de proteção e risco, de natureza biológica, psicológica e social.

Um fator de risco pode afetar múltiplas áreas da vida, ser potencializado por outros fatores adversos ou ser neutralizado mediante fatores de proteção. "A ação e a interação entre estes determinam a idiossincrasia dos padrões de consumo. Nunca um fator isolado responderá pela presença de um padrão problemático de uso: é necessário que um conjunto de fatores propicie o seu aparecimento" (Ribeiro, Laranjeira e Messas, 2013, p.9).

A maior parte dos alunos participantes deste estudo que consomem álcool revelou que nunca perdeu alguma função, não teve amnésia alcoólica, não gerou prejuízos a terceiros, nunca foi chamado atenção por alguma pessoa próxima por causa do uso bebida alcoólica. Este é outro resultado bastante favorável a esse público entrevistado, que está liberto não apenas de perda de função, mas de diversas doenças. Tal fato se corrobora na Classificação Estatística Internacional de Doenças e Problemas Relacionados à Saúde, 10a revisão (CID-10) que publica que o álcool é responsável por mais de 230 tipos de doenças. O seu uso nocivo é responsável por 7,2\% de enfermidades para homens e por 2,2\% para mulheres. O álcool ocasiona 
em média 3 milhões de mortes no mundo anualmente, além de milhões de mortes prematuras, e anos vivenciados com doenças crônicas ou sequelas de lesões fatais. Dentre os indivíduos de 15 a 49 anos de idade, o álcool é responsável por 10\% dos óbitos no mundo. O contexto do consumo, a frequência, a quantidade de álcool aumentam o risco de problemas de saúde e sociais, agudos e crônicos (Monteiro, 2020).

A minoria dos alunos participantes do estudo consome 5 ou mais doses de bebidas alcoólicas em uma única ocasião e confirma sentir culpa ou remorso pela ingestão de bebidas alcoólicas nos últimos 12 meses. Cita-se o estudo de Rebouças et al., (2021) que avaliaram a prática de binge drinking entre universitários numa universidade pública estadual da Bahia. O termo binge drinking ou bebedeira refere-se "ao uso excessivo e episódico do álcool, com alternância entre períodos de grande consumo e abstinência, " cuja prática é muito comum entre universitários. O binge drinking associa-se a comportamentos de risco, como dirigir alcoolizado, absentismo, vandalismo, sexo desprotegido e acidentes. A amostra desse estudo contou com 150 universitários de ambos os gêneros que afirmaram ingerir bebidas alcoólicas, sendo a média de idade de 23,2 anos. Os dados também evidenciaram uma associação entre beber para amenizar a ansiedade e a prática do binge drinking.

Ainda para o estudo de Rebouças et al., (2021), quanto ao uso moderado do álcool, os universitários relataram sentir apenas sonolência após o consumo da bebida; aqueles que faziam o uso nocivo relataram sensação de alegria. No consumo do binge drinking, $41 \%$ eram mulheres e 59\% eram homens. A diferença significativa para o sexo masculino envolveu: ter sofrido ou ocasionado prejuízos a terceiros. Já o sexo feminino foi conseguir benefício social e esconder dos pais o uso excessivo do álcool. Alguns fatores de risco para o binge drinking foram citados, são eles: gênero, começo precoce do uso do álcool, influência dos pares e ingresso na universidade. Enquanto os fatores de proteção envolveram o fato de estar casado e assíduo em alguma religião. Ressaltam-se que a prática do binge drinking por universitários ainda requer muitos estudos competentes a apontar o papel que o ingresso no meio acadêmico exerce nessa conduta cada vez mais frequente. Ainda há uma escassez de trabalhos capazes de estabelecer o perfil do universitário que adota essa prática, e, suas possíveis consequências no desempenho acadêmico.

No Brasil, de modo geral, a população evidencia elevado consumo médio diário de bebidas alcoólicas (Trigo e Santiago, 2021). Ressalta-se ainda sobre "a necessidade de reduzir a visão amplamente aceita de que o consumo leve a moderado de álcool não é nocivo à saúde, no sentido de adotar cautela em tal proposição. Assim, as pessoas que fazem uso leve ou não consomem não podem ser encorajadas a esperar benefício substancial da ingestão de bebidas alcoólicas. Em contrapartida, para os que já consomem, recomenda-se moderação, evitando episódios de consumo pesado (binge drinking) " (Souza e Souza, 2021, p.4845).

A grande maioria dos alunos participantes do presente estudo nunca fumou um cigarro de tabaco, ou Nicotiana tabacum que é uma planta da qual é extraída uma substância denominada nicotina que ao ser tragada pelo fumante é aspirada pelos pulmões, podendo chegar ao cérebro em cerca de nove segundos e afetar o sistema nervoso central, causar alteração no humor e reduzir o apetite (Divisão Estadual de Narcóticos, 2021).

Entre a minoria dos alunos que fuma, a maioria revela ter sido influenciada por amigos e colegas. Porém, as pessoas ainda não se encontram preparados para circunstâncias que evidenciam diagnósticos que abrangem riscos de morte, como é o caso de um câncer causado pelo tabagismo, cujo diagnóstico causa diferentes efeitos nas pessoas, em seus familiares e amigos. O câncer motivado pelo cigarro pode acontecer em qualquer parte do corpo. Mas, "certos órgãos costumam ser mais afetados do que outros. E, cada órgão poderá ser invadido por diferentes tipos de tumores, mais ou menos afetados, e classificados de acordo com a parte principal do tumor" (Nascimento, 2021, p.3).

Importante, então, para aqueles que não fumam prosseguirem firmes em seu propósito de não serem influenciados por outrem e cair no vício do tabaco, situação que não é nada simples, pois, segundo a Revisão da Classificação Estatística Internacional de Doenças e Problemas Relacionados à Saúde (CID-10), o tabagismo compõe o grupo de transtornos mentais e 
comportamentais devido ao consumo de substância psicoativa. Também, conforme a Organização Mundial da Saúde, o tabaco mata cerca de 8 milhões de indivíduos anualmente. Mais de 7 milhões dessas mortes procedem do seu uso direto, e, aproximadamente 1,2 milhão procede de fumantes passivos. No mundo, em média, $80 \%$ dos mais de um bilhão de fumantes residem em países de baixa e média renda nos quais a incidência de enfermidades e mortes associadas ao tabaco é maior (Brasil, 2021). Em grande parte da América do Sul, o tabaco é um sério fator de risco de morte, principalmente no Brasil, que está no segundo lugar com cerca de 200.000 mortes anuais, sendo que destas, 7 pessoas em média morrem todos os dias (Nascimento, 2021).

Os alunos revelaram fumar cigarros nas instalações/propriedades da universidade, fato que pode prejudicar as pessoas que frequentam aquele ambiente, isso devido a fumaça do cigarro possuir mais de 4.700 substâncias tóxicas, como: monóxido de carbono, formol, naftalina, alcatrão, cujo uso frequente aumenta a incidência de doenças como pneumonia, câncer em diferentes órgãos, "infarto de miocárdio, bronquite, enfisema pulmonar, derrame cerebral, úlcera digestiva (...), náuseas, dores abdominais, diarreia, vômitos, cefaleia, tontura, braquicardia e fraqueza" (Divisão Estadual de Narcóticos, 2021, p.1). Para além disso, a fumaça ativa é distinguida pela fumaça central que é provocada pela alta temperatura. Ao 'tragar' o cigarro, a fumaça passa pelo filtro, entra nos pulmões e, em seguida, se dissemina no ambiente (Nascimento, 2021).

Muito embora a grande maioria da amostra desse estudo seja composta pelo gênero feminino, é de extrema importância que os alunos venham a refletir sobre os danos do tabagismo para o sexo masculino. O estudo de Souza et al., (2021) revela que o gênero masculino apresenta maior risco de ir a óbito pelo tabagismo. O que estabelece uma possível elucidação para esse achado, incide na tendência dos homens em buscar por cuidados médicos mais tardiamente ou ainda ignorar os sintomas de determinadas doenças. A mulher, costuma ter estilos de vida mais saudáveis e procura com maior frequência os serviços de saúde, tanto de promoção ou prevenção e assistência. Esse estudo ainda destaca que a inatividade física, o consumo excessivo de álcool e o tabagismo tendem a acontecer respectivamente.

Compete, sobretudo, aos futuros odontologistas tabagistas refletirem sobre o consumo do tabaco e o câncer de boca. Segundo Leite et al., (2021) essa associação tem relação bem fundamentada na literatura mundial, cujo consumo é um fator de risco independente para desenvolver o câncer, uma vez que, contribui para aumentar o risco respectivo em sete a dez vezes a ser comparados com um indivíduo não fumante. Ao fumar, tem-se o risco de desenvolver câncer aumentado, entretanto, esse aumento sujeita-se a quantidade e duração de uso diário, pois refere-se a um efeito dose-dependente.

Os alunos participantes do estudo revelaram fazer uso de tabaco para mascar, rapé, narguilé, charutos e cachimbos. Leite et al., (2021) advertem que, em média 90\% das pessoas que apresentam câncer de boca ou garganta fazem o consumo de cachimbos, charutos, cigarros ou mascam tabaco. O costume de mascar fumo aumenta sobremodo considerável a probabilidade de desenvolver câncer bucal, uma vez que, o tabaco para mascar tem formulas com $\mathrm{pH}$ alcalino, o que torna mais fácil a absorção da nicotina pela mucosa bucal.

O uso do tabaco é considerado um transtorno médico crônico (CID-10 F17) e pode trazer, juntamente, problemas para a saúde bucal. Entretanto, apesar do evidente efeito adverso do tabaco nos tecidos periodontais de suporte, a periodontite relacionada ao fumo não se refere a uma doença distinta. "O tabagismo é avaliado como um fator modificador da periodontite e deve ser incluído em um diagnóstico clínico de periodontite como descritor, devendo esses pacientes serem classificados quanto ao consumo atual ou passado de tabaco em maços/ano" (Moreira, 2020, p.22-3).

Quando se associa tabaco e álcool, cabe ressalvar que, conforme Leite et al., (2021), o etanol aumenta a permeabilidade da mucosa bucal, tornando mais fácil a absorção de substância cancerígena no tecido epitelial, trazendo efeitos danosos para a saúde sistêmica e bucal. Pessoas que fazem o consumo do álcool, porém, não fumam, pode não correr o risco de carcinogênese bucal. Na mucosa bucal de fumantes que usam álcool é alta a incidência de carcinogênese, isso porque a ação 
o álcool pode ocasionar a redução da imunidade da mucosa e facilitar o ingresso de agentes carcinogênicos do tabaco nos tecidos, o que acelera o metabolismo de substâncias cancerígenas, das prostaglandinas e das células de Langerhans.

Montes et al., (2015) corroboram que as consequências do consumo de álcool e tabaco encontram-se relacionadas a diferentes agravos em saúde bucal, da estética do sorriso, e até a predisposição ao câncer bucal. O tabagismo é o fator de risco principal para carcinoma espinocelular de cabeça e pescoço, sendo que a maior parte dos casos de câncer nessas regiões devem-se à combinação dos hábitos de fumar e beber.

Em correspondência, outro estudo identificou e analisou se os sintomas de ansiedade, estresse e depressão encontramse associados com uso de substâncias lícitas e ilícitas em universitários da área da saúde. A pesquisa contou com 111 universitários da área da saúde de uma universidade da região do Rio Grande do Sul. Os dados mostraram que as drog as mais usadas foram álcool, tabaco e maconha, sendo o álcool aquele que mais pontuou. Ocorreram correlações significativas entre o uso de drogas com sintomas de ansiedade e estresse. Torna-se necessário dar atenção especial para o uso dessas substâncias feito por universitários da área da saúde, pois, este pode ocasionar danos à vida pessoal, acadêmica e profissional desses estudantes (Beneton et al., 2021).

Em perspectiva análoga, Montes et al., (2015) avaliaram o uso de álcool e tabaco entre os acadêmicos de odontologia. A amostra contou com 300 acadêmicos da UFPR, sendo que houve maior prevalência no consumo de álcool e tabaco, pelo gênero masculino, de classes sociais mais abastadas, que residiam longe da família. Os autores apontaram que alguns fatores podem influenciar no consumo álcool e tabaco nesta fase, como mudança de fase, novas amizades e intensa atividade social. A pressão por bons resultados e a competição para a vida profissional podem levar ao uso dessas substâncias, visando, controversamente, reduzir o estresse e a ansiedade. Esse fato pode reduzir o rendimento escolar, elevar os riscos de acidentes de trânsito, de violência urbana, e, ainda motivar condutas de risco como a prática sexual desprotegida. Esse contexto, ainda aumenta o risco de depressão e ansiedade, compromete aspectos cognitivos, comportamentais e emocionais do indivíduo.

Uma unanimidade de autores concorda que o consumo de álcool e tabaco é avaliado como um problema de saúde pública e estabelece um fator de risco relevante para inúmeras doenças, além de propiciar diferentes problemas comportamentais, mentais e físicos (Montes et al., 2015, Moreira, 2020; Beneton et al., 2021; Nascimento, 2021; Souza et al.,2021).

\section{Conclusão}

Os dados alcançados através deste estudo refutam a hipótese de que seria alto o consumo de álcool e o risco de dependência dessa substância pelos estudantes de Odontologia do Centro Universitário de Patos de Minas - UNIPAM, pois, o score do questionário AUDIT, revelou-se baixo, fato que não deixa de ser um alento, pois a pesquisa permitiu vislumbrar uma geração mais liberta do consumo de álcool no período acadêmico.

Para a minoria de alunos revelada neste estudo, que faz o uso moderado de álcool, espera-se que a mesma esteja alerta, pois, o consumo do álcool pode passar de moderado a alto, já que o álcool é uma substância altamente possível de levar ao vício. Por isso a importância de se propor programas de educação e ações preventivas que visem todos os tipos de consumo, objetivando esclarecer esse risco e ratificar os perigos do seu uso inadequado, sobretudo, para jovens universitários que em diversos estudos revelam-se como grupo de risco.

De acordo com os resultados obtidos, nenhuma diferença quanto ao consumo de álcool e tabaco foi percebida entre os diferentes períodos do curso de Odontologia do UNIPAM comparados e avaliados. As universidades, de maneira geral, poderiam compreender o seu relevante papel nesse contexto, cabendo promover atividades culturais e facilitar o acesso ao conhecimento referente aos riscos de qualquer tipo de consumo de álcool e tabaco, de forma a reduzir ou eliminar seu uso 
nesse público. Torna-se importante haver propostas de políticas de saúde, não apenas em termos de prevenção primária, mas, também em termos de prevenção secundária e gestão de sistemas de saúde.

Sugere-se realizar um estudo que identifique estratégias de reconhecimento desses hábitos deletérios e o ponto de partida para adoção de medidas de promoção de saúde e prevenção de agravos do uso de álcool e tabaco entre universitários.

\section{Referências}

Beneton, E. R., Schmitt, M, \& Andretta, I. (2021) Sintomas de depressão, ansiedade e estresse e uso de drogas em universitários da área da saúde. SPAGESP Sociedade de Psicoterapias Analíticas Grupais do Estado de São Paulo Revista da SPAGESP, 22(1),145-159.

Brasil. Ministério da Saúde. Instituto Nacional de Câncer. (2021). Tabagismo. Última modificação: 04/03/2021.12h39.

Divisão Estadual de Narcóticos - DENARC. (2021). Tabaco - Definição e Generalidades.

Grupo Colaborativo para a Pesquisa Mundial sobre Tabagismo em Adultos. (2011). Perguntas sobre tabaco para pesquisas: Um subconjunto de perguntas chave da Pesquisa Mundial sobre Tabagismo em Adultos (Global Adult Tobacco Survey - GATS), 2a ed. Atlanta, GA: Centros de Prenvenção e Controle de Doenças dos Estados Unidos.

Ham, L. S., \& Hope, D A. (2003). College students and problematic drinking: A review of the literature. Department of Psychology, University of NebraskaLincoln, Lincoln, NE 68588-0308, USA.

Lima, M. M. L. E., Prado, P. H. C. O., Abreu, R. T., \& Monteiro, J. B. (2020). Influência do estresse emocional na saúde bucal de estudantes universitários. V Jornada de Iniciação Científica. Sociedade, Ciência e Tecnologia. Anais do VI Seminário Científico do Unifacig. n. 6.

Leite, R. B., Marinho, A.C., Costa, B. L., Laranjeira, M. B.V., Araújo, K. D. T., \& Cavalcanti, A. F. M. (2021). A influência da associação de tabaco e álcool no câncer bucal: revisão de literatura. J. Bras. Patol. Med. Lab., 57(10), e214.

Lima, C.T., \& Freire, A.C. (2005). Concurrent and construct validity of the audit in an urban brazilian sample. Alcohol. 40(6),584-589

Maia, B. R., \& Dias, P. C. (2020). Ansiedade, depressão e estresse em estudantes universitários: o impacto da Covid-19. Estud. psicol. Campinas, 37(08), e200067.

Méndez, E. B. (1999) Uma versão brasileira do Audit - Alcohol Use DisordersIdentification Test. Dissertação de Mestrado não publicada, Universidade Federal de Pelotas, RS.

Mendonça, C. (2021). Abordagem ao consumo de álcool em consulta - sessões clínicas Sesaram - Serviço De Saúde EPE de RAM, Portugal, 1-26.

Monteiro, M. G. A. (2020). Iniciativa Safer da Organização Mundial da Saúde e os desafios no Brasil para a redução do consumo nocivo de bebidas alcoólicas. Epidemiol. Serv. Saúde 29(1), e2020000.

Montes, G. R., Gonzales, J. A., Ferreira, F. M., Assunção, L. R. S., Bonotto, D. M. V., \& Fraiz, F. C. (2015). Perfil socioeconômico dos acadêmicos de Odontologia usuários de álcool e tabaco. Revista da ABENO 15 (3), 88-97.

Moreira, T. C. Classificação das doenças periodontais 1999 versus 2017. (2020). Artigo (Bacharel em Odontologia). Curso de Graduação em Odontologia da UniCesumar. Centro Universitário de Maringá, Maringá.

Nascimento, V. N., Faria, G., \& Lima, M. K. D. G. (2021). Tabagismo na juventude: uma revisão bibliográfica. Revista Artigos. Com, 26 , p. e6693.

Pennachioni, N. P., Volpato, R. J., Zerbetto, S. R., Barroso, T. M. D., \& Gonçalves, A. M. S. (2021). Adaptação transcultural e validação da Escala de Expectativas Positivas sobre o uso do Álcool no Brasil. Portal de Eventos CoPICT - UFSCar, XXVII CIC e XII CIDTI.

Pillon, S. C., \& Corradi-Webster, C. M. (2006) Teste de identificação de problemas relacionados ao uso de álcool entre estudantes universitários. $R$ Enferm UERJ, Rio de Janeiro, 14(3), 325-32.

Rebouças, E. C. C., Pereira, T. N., Lisbôa, D. K. M., \& Almeida Filho, R. L. S. (2021). O binge drinking por universitários: perfil do estudante e fatores de risco e proteção. REFACS (online) 9(4).

Rodrigues, H.S., Amorim, I.A., Barbosa, J. S. P., Martins, K. R., Valle, L.A., \& Pereira, L.C. (2021) Consumo de drogas ilícitas e a relação com a doença periodontal estudo de revisão. Brazilian Journal of Health Review, Curitiba, 4 (2), 5353-5365.

Rehm, J., Gmel, G.E., Gmel, G., Hasan, O. S., Imtiaz, S., Popova, S. et al. (2017) The relationship between different dimensions of alcohol use and the burden of disease-an update. Addiction. Toronto, Ontario, Canada, 112 (6), 968-1001,

Ribeiro, M., Laranjeira, R., \& Messas, G. (2013). Transtornos relacionados ao consumo de álcool e outras drogas. Unidade de Pesquisa em Álcool e Drogas (UNIAD - UNIFESP), 29p.

Rizzieri, B. S. R., \& Afonso, L. F. R. (2011). Comportamento de risco em jovens universitários. Jornal Psicologia em Foco.

Santos, R. N. Habilidades sociais e ansiedade em universitários na pandemia de Covid-19 (2021). Dissertação (Mestrado em Psicologia - Processos Psicológicos e Saúde). Programa de pós-graduação em Psicologia. Universidade Federal do Amazonas, Manaus (AM). 
Research, Society and Development, v. 10, n. 17, e25101724320, 2021

(CC BY 4.0) | ISSN 2525-3409 | DOI: http://dx.doi.org/10.33448/rsd-v10i17.24320

Souza e Souza, L. P., Hermsdorff, H. H. M., Miranda, A. E. S., Bressan, J., \& Pimenta, A. M. (2021). Consumo de bebidas alcoólicas e excesso de peso em adultos brasileiros - Projeto CUME. Ciência \& Saúde Coletiva, 26(Supl. 3), 4835-4848.

Souza, A. C. L. G., Bortolotto, C. C., Bertoldi, A. D., Tomas, E., Demarco, F. F., \& Gonzalez, M. C. (2021) Mortalidade por todas as causas em um período de três anos entre idosos não institucionalizados do Sul do Brasil. Rev Bras Epidemiol 24, E210015.

Silva, J. G. A. R., \& Romarco, E. K. S. (2021). Análise dos níveis de ansiedade, estresse e depressão em universitários da Universidade Federal de Viçosa (UFV). Instrumento: Rev. Est. e Pesq. em Educação, Juiz de Fora, 23 (1) 134-150.

Saunders, J.B., \& Aasland, O. G. (1993). Development of the Alcohol Use Disorders Identification Test (AUDIT): WHO Collaborative Project on Early Detection of Persons with Harmful Alcohol Consumption--II. Addiction. 88(6),791-804.

Trigo, A. C., \& Santiago, L. M. (2021) Consumo de álcool nos estudantes do ensino superior de Coimbra, Acta Med Port Universidade de Coimbra, 1-9, 34(AOP)

Wagner, G. A., \& Andrade, A. G. (2008). Uso de álcool, tabaco e outras drogas entre estudantes universitários brasileiros. Rev. psiquiatr. clín., .35 (suppl.1) 48-54. 